\title{
Matched comparison of next- and early-generation balloon- expandable transcatheter heart valve implantations in failed surgical aortic bioprostheses
}

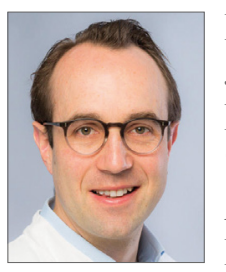

Moritz Seiffert ${ }^{1}, \mathrm{MD}$; Hendrik Treede ${ }^{2}, \mathrm{MD}$; Joachim Schofer ${ }^{3}, \mathrm{MD}$; Axel Linke${ }^{4}$, MD; Jochen Wöhrle ${ }^{5}$, MD; Hardy Baumbach ${ }^{6}$, MD; Julinda Mehilli ${ }^{7}$, MD; Vinayak Bapat ${ }^{8}$, MD; Matheus Simonato; ${ }^{9}$ Thomas Walther ${ }^{10}$, MD; Mathias Kullmer ${ }^{11}$, MD; Peter Boekstegers ${ }^{12}$, MD; Stephan Ensminger ${ }^{13}$, MD; Thomas Kurz ${ }^{14}$, MD; Helene Eltchaninoff ${ }^{15}$, MD; Ardawan Rastan ${ }^{16}$, MD; Nicolas Werner ${ }^{17}$, MD; Arend de Weger ${ }^{18}$, MD; Christian Frerker ${ }^{19}$, MD; Bernward Lauer ${ }^{20}$, MD; Olivier Muller ${ }^{21}$, MD; Brian Whisenant ${ }^{22}$, MD; Arun Thukkani ${ }^{23}$, MD; Giora Weisz ${ }^{24}, \mathrm{MD}$; Danny Dvir ${ }^{9,25 *}, \mathrm{MD}$

1. University Heart Center Hamburg, Hamburg, and DZHK (German Center for Cardiovascular Research), partner site Hamburg/Kiel/Lübeck, Hamburg, Germany; 2. University Hospital Halle, Halle (Saale), Germany; 3. Albertinen Heart and Vascular Center, Hamburg, Germany; 4. Heart Center Dresden, Technical University Dresden, Dresden, Germany; 5. University of Ulm, Ulm, Germany; 6. Robert-Bosch-Hospital, Stuttgart, Germany; 7. Department of Cardiology, Munich University Clinic, Ludwig-Maximilians University, Munich, and DZHK (German Center for Cardiovascular Research), partner site Munich Heart Alliance, Munich, Germany; 8. Columbia University, New York, NY, USA; 9. St. Paul's Hospital -University of British Columbia, Vancouver, British Columbia, Canada; 10. Kerckhoff Heart Center, Bad Nauheim, Germany; 11. Heart Center Duisburg, Duisburg, Germany; 12. HELIOS Heart Center Siegburg, Siegburg, Germany; 13, Heart and Diabetes Center NRW, Bad Oeynhausen, Germany; 14. University Heart Center Lübeck, Lübeck, Germany; 15, Rouen University Hospital, Rouen, France; 16. Cardiovascular Center Rotenburg, Rotenburg, Germany; 17. Klinikum Ludwigshafen, Ludwigshafen, Germany; 18. Leids Universitair Medisch Centrum, Leiden, the Netherlands; 19. Asklepios Hospital St. Georg, Hamburg, Germany; 20. Zentralklinik, Bad Berka, Germany; 21. Lausanne University, Lausanne, Switzerland; 22. University of Utah, Salt Lake City, UT, USA;

23. Missouri Baptist Hospital, St. Louis, MS, USA; 24. Shaare Zedek Medical Center, Jerusalem, Israel; 25. University of Washington, Seattle, WA, USA

This paper also includes supplementary data published online at: http://www.pcronline.com/eurointervention/137th_issue/71

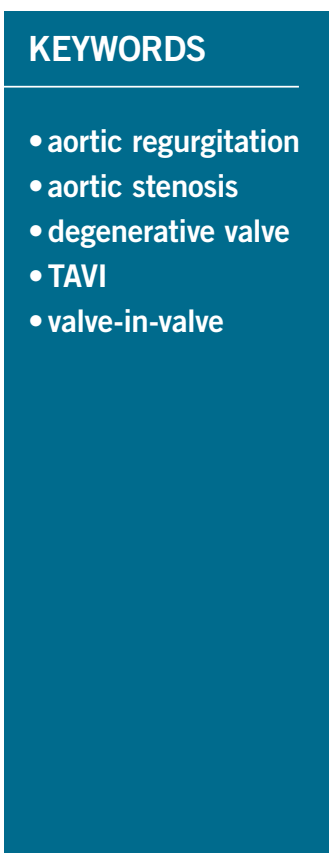

\section{Abstract}

Aims: Transcatheter valve-in-valve implantation (VinV) is established for the treatment of degenerated surgical bioprostheses in patients at high operative risk. Our aim was to report on the first large assessment of VinV with next-generation balloon-expandable transcatheter heart valves.

Methods and results: After SAPIEN XT or SAPIEN 3 VinV, 514 patients were analysed using an inverse probability of treatment weighting. Standardised clinical and haemodynamic outcomes were compared, and core laboratory evaluation of implantation depth was performed. Thirty-day all-cause mortality was $0.6 \%$ and $3.5 \%$ for SAPIEN 3 and SAPIEN XT ( $\mathrm{p}=0.077$ ). Residual transprosthetic gradient $\geq 20 \mathrm{mmHg}$ was observed in $38.3 \%$ (SAPIEN 3) and $35.7 \%$ (SAPIEN XT) of patients $(\mathrm{p}=0.627)$ with increased rates in small bioprostheses ( $\leq 21 \mathrm{~mm}$ true ID). In SAPIEN 3 VinV, low implantation depth $>20 \%$ THV stent frame length was associated with a higher rate of elevated transaortic gradients $(\mathrm{p}=0.048)$. Similarly, an implantation depth $>5 \mathrm{~mm}$ was linked to more pacemaker implantations $(\mathrm{p}=0.01)$. Overall, a trend towards higher pacemaker implantation rates was observed after SAPIEN $3 \operatorname{VinV}(6 \%$ vs. $2.5 \%$ in SAPIEN XT, $\mathrm{p}=0.071)$.

Conclusions: Transcatheter aortic VinV with the balloon-expandable SAPIEN XT or SAPIEN 3 was similarly safe and effective. However, residual stenosis remains a concern, particularly in smaller bioprostheses and with increasing implantation depth.

\footnotetext{
*Corresponding author: University of Washington, 1959 NE Pacific Street, C502-A, Box 356422, Seattle, WA 98195-6422, USA. E-mail:danny.dvir@gmail.com
} 


Abbreviations
$\begin{array}{ll}\text { CI } & \text { confidence interval } \\ \text { iEOA } & \text { indexed effective orifice area } \\ \text { IPT } & \text { inverse probability of treatment } \\ \text { ROC } & \text { receiver operating characteristic } \\ \text { STS-PROM } & \text { Society of Thoracic Surgeons predicted risk of } \\ & \text { mortality score } \\ \text { TAVI } & \text { transcatheter aortic valve implantation } \\ \text { THV } & \text { transcatheter heart valves } \\ \text { VARC-2 } & \text { Valve Academic Research Consortium-2 } \\ \text { VinV } & \text { valve-in-valve } \\ \text { VIVID } & \text { Valve-in-Valve International Data }\end{array}$

\section{Introduction}

Valve-in-valve (VinV) implantation of transcatheter heart valves (THV) has become an established therapy for the treatment of degenerated surgical bioprostheses in patients at high operative risk. With the increasing selection of bioprostheses over mechanical valves in younger patients undergoing surgical valve replacement ${ }^{1}$, a large number of patients is expected to require redo valve procedures to treat structural valve degeneration within the next decade. Broad experience has been gained with the CoreValve ${ }^{\circledR}$ (Medtronic, Minneapolis, MN, USA) and SAPIEN XT (Edwards Lifesciences, Irvine, CA, USA) platforms in VinV procedures ${ }^{2}$. Limitations of the procedure include a need for precise positioning, the risk of coronary obstruction and - foremost - residual stenosis. Elevated post-procedural gradients and prosthesis-patient mismatch are commonly observed after VinV procedures, especially in procedures performed utilising balloon-expandable devices in small surgical bioprostheses ${ }^{2,3}$.

The next-generation balloon-expandable SAPIEN 3 THV (Edwards Lifesciences) has demonstrated promising clinical outcomes in native aortic valve stenosis and is currently the most widely used THV device in transcatheter aortic valve implantation (TAVI) procedures worldwide. Prominent new features of this device include an outer polyethylene terephthalate cuff at the inflow portion of the THV that minimises paravalvular leakage and a longer stent frame profile that shortens significantly during balloon inflation. However, paravalvular leakage is rarely a concern in VinV procedures in comparison to conventional TAVI procedures ${ }^{2}$, while the longer device frame may result in lower implantation with part of the THV stent extending into the left ventricular outflow tract, resulting in conduction defects ${ }^{4}$. At present, the feasibility of using SAPIEN 3 for VinV therapy is limited to case reports and small case series.

The objective of this study was to evaluate the safety and efficacy of the newest-generation balloon-expandable THV, the SAPIEN 3, for VinV treatment of degenerated aortic surgical bioprostheses in comparison to the earlier-generation SAPIEN XT.

Editorial, see page 377

\section{Methods \\ REGISTRY DESIGN}

The Valve-in-Valve International Data (VIVID) registry is an ongoing investigator-initiated global registry of VinV procedures including different THV devices and valve positions ${ }^{2}$. Contribution of anonymised patient data to the VIVID registry was performed according to local ethics committee requirements. Data inconsistencies were resolved with local investigators.

\section{PATIENT SELECTION}

Only cases performed in the aortic position and using the balloon-expandable SAPIEN 3 and SAPIEN XT devices are included. We estimate propensity score inverse probability of treatment (IPT) weights to adjust for baseline characteristics between SAPIEN 3 and SAPIEN XT patients (Supplementary Appendix for statistical analysis and inverse probability of treatment weighting process).

\section{DEFINITIONS}

Patients' risk of operative mortality was calculated using the Society of Thoracic Surgeons predicted risk of mortality score (STS-PROM) (http://riskcalc.sts.org/stswebriskcalc/). The mechanism of prosthetic valve failure was evaluated according to echocardiographic guidelines and defined as regurgitation, stenosis or mixed ${ }^{5}$. Body surface area was calculated according to the Mosteller formula and included in the calculation of the indexed effective orifice area (iEOA). True internal diameter bioprostheses specifications were retrieved from the valve-in-valve application version $2.0^{6}$. Standardised clinical and haemodynamic outcomes were defined according to the updated Valve Academic Research Consortium definitions (VARC-2) ${ }^{7}$ and compared between SAPIEN 3 and SAPIEN XT groups. Early post-implantation haemodynamic data were obtained from intraprocedural or early post-procedural echocardiograms.

\section{IMPLANTATION DEPTH ANALYSIS}

Implantation depth was assessed by an experienced operator blinded to clinical results in a central core laboratory (St. Paul's Hospital, Vancouver, Canada), as previously described ${ }^{8}$. Briefly, fluoroscopic images were obtained from all centres. Images of 90 procedures (57.7\% of SAPIEN 3 cases) with sufficient resolution, perpendicularity of THV and adequate radiopaque markers of the surgical prostheses were analysed. For each SAPIEN 3, one vertical line was traced on each side of the device. The values were added, and their average was considered the height of the device. Another line was traced at each side of the THV starting from the bottom of the surgical valve ring to the bottom of the THV. The values were added, and their average was considered the depth numeric value. The depth numeric value was divided by the height of the device frame, thus obtaining the relative depth. An absolute depth value was estimated by multiplying the relative depth value by the height of a nominally expanded SAPIEN 3 device (15.5 $\mathrm{mm}$ for the $20 \mathrm{~mm}$ THV, $18 \mathrm{~mm}$ for the $23 \mathrm{~mm}$ THV, $20 \mathrm{~mm}$ for the $26 \mathrm{~mm} \mathrm{THV}$, and $22.5 \mathrm{~mm}$ for the $29 \mathrm{~mm} \mathrm{THV}$ ). 
Receiver operating characteristic (ROC) analysis was used to determine the appropriate depth of implantation cut-off for pacemaker risk and elevated mean gradient $(\geq 30 \mathrm{mmHg}$ ). AUC values were 0.63 for optimal implant depth (standard error 0.086; $95 \%$ confidence interval $[\mathrm{CI}]: 0.465-0.801 ; \mathrm{p}=0.22$ ) and 0.77 for decreased pacemaker rate (standard error 0.103 ; 95\% CI: $0.564-$ $0.969 ; \mathrm{p}=0.01$ ) in SAPIEN 3 cases.

\section{Results}

\section{PATIENT CHARACTERISTICS}

From a total of 541 aortic VinV procedures with balloon-expandable devices in the VIVID registry, 514 cases (95.0\%) (144 SAPIEN 3 and 370 SAPIEN XT) had complete baseline characteristics used to fit the propensity score model. Patient demographics (Table 1) had negligible to small differences between SAPIEN 3 and SAPIEN XT patients before and after IPT weighting. Propensity scores had sufficient common support not to exclude any observations, ranging from 0.18 to 0.81 for SAPIEN XT with a median of 0.23 and from 0.058 to 0.52 for SAPIEN 3 with a median of 0.26 (Supplementary Figure 1). After IPT weighting, patients presented at a mean age of $76.2 \pm 7.1$ (SAPIEN 3) and 76.9 \pm 14.1 (SAPIEN XT) years and at a median of 10 (CI: 7-13) years after initial surgical aortic valve replacement for the treatment of bioprosthesis degeneration. Degeneration mode was equally distributed among predominant stenosis, regurgitation or a combination of both. Surgical prostheses were stented

Table 1. Balance in baseline covariates.

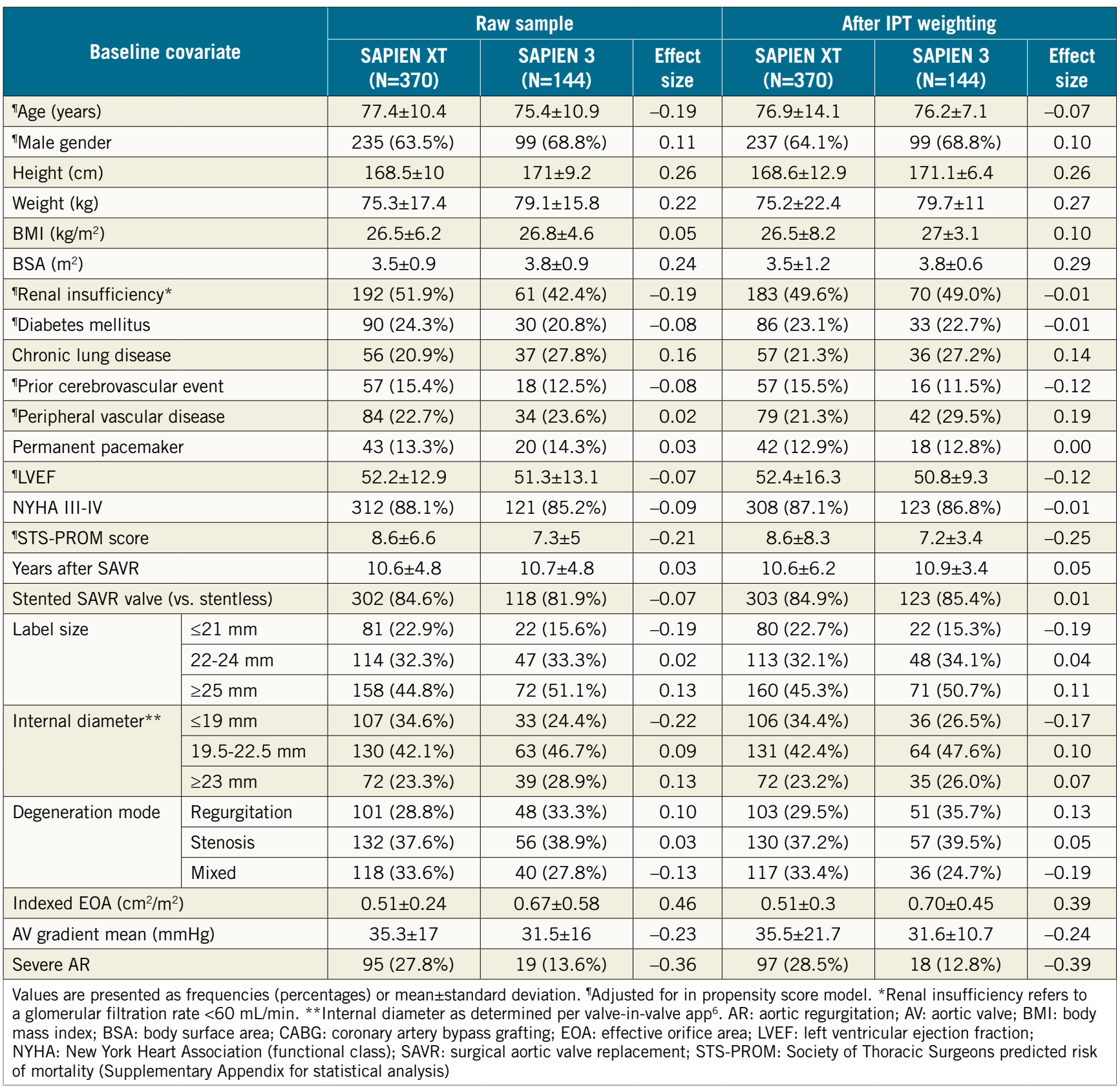


in the majority of cases (Supplementary Table 1 for list of degenerated bioprostheses). No significant differences were observed with regard to label size or true internal diameters between groups.

\section{PERIPROCEDURAL PARAMETERS}

After IPT weighting, VinV procedures were performed via transfemoral access in $88.2 \%$ (SAPIEN 3) and 58.5\% (SAPIEN XT, $\mathrm{p}<0.001$ ) of cases (Table 2). General anaesthesia was employed in 52.5\% (SAPIEN 3) and 75.0\% (SAPIEN XT, p<0.001). Transoesophageal echocardiographic guidance was performed in $53.5 \%$ (SAPIEN 3) and $74.7 \%$ (SAPIEN XT, $\mathrm{p}<0.001$ ) of procedures. Predilation of the degenerated bioprostheses was performed in $27.0 \%$ (SAPIEN 3) and $29.3 \%$ (SAPIEN XT, $\mathrm{p}=0.618$ ) of cases. The $23 \mathrm{~mm}$ THV was the most commonly selected size for VinV implantation in both groups, being chosen in $67.8 \%$ (SAPIEN 3) and $60.2 \%$ (SAPIEN XT, $\mathrm{p}=0.395$ ). Post-dilation $(4.7 \%$ and $1.2 \%$, $\mathrm{p}=0.033$ ) and implantation of a second valve due to displacement or suboptimal function $(3.2 \%$ and $0.4 \%, \mathrm{p}=0.052)$ were rare for both groups but more common for SAPIEN XT procedures. Coronary obstruction occurred in no patient during implantation of a SAPIEN 3 and in eight patients of the SAPIEN XT group (Freestyle $^{\mathrm{TM}}$ [Medtronic], Toronto ${ }^{\circledR}$ [St. Jude Medical, St. Paul, MN, USA], PERIMOUNT [Edwards Lifesciences]).

\section{HAEMODYNAMIC RESULTS}

Aortic regurgitation (>mild) was reduced from $44.3 \%$ at baseline to $2.1 \%$ of patients after VinV (SAPIEN 3, $<<0.001$ ) and from $48.8 \%$ to $5.2 \%$ (SAPIEN XT, p<0.001) (Table 2). Effective orifice areas improved $0.330 \mathrm{~cm}^{2} / \mathrm{m}^{2}$ (SAPIEN 3) and $0.223 \mathrm{~cm}^{2} / \mathrm{m}^{2}$ (SAPIEN XT) $(p=0.007)$. Mean transvalvular gradients decreased $14.7 \mathrm{mmHg}$ (SAPIEN 3) and $18.1 \mathrm{mmHg}$ (SAPIEN XT). A residual transprosthetic gradient $\geq 20 \mathrm{mmHg}$ was observed in $38.3 \%$ (SAPIEN 3) and $35.7 \%$ (SAPIEN XT) of patients $(\mathrm{p}=0.627$ ). An association of elevated residual gradients and small surgical bioprostheses was noted with both devices (Figure 1A-Figure 1C). For SAPIEN 3, low implantation (defined as $>20 \%$ THV stent length) was additionally associated with elevated gradients $(p=0.049)$ (Figure 2, Figure 3A). Elevated residual gradients $\geq 20 \mathrm{mmHg}$ were also observed more frequently after VinV treatment of stenosed bioprostheses vs. regurgitation and mixed ( $42.6 \%$ vs. $33.9 \%$ overall, $\mathrm{p}=0.053)$ and stented vs. stentless valves $(39.3 \%$ vs. $24.7 \%, \mathrm{p}=0.013)$. Of note, a low implantation of the SAPIEN 3 was intended in two patients to alleviate parasurgical valve regurgitation and successfully carried out. One-year follow-up demonstrated a mean gradient of $18 \pm 9.1 \mathrm{mmHg}$ for SAPIEN 3 patients, with an associated aortic valve area of $1.24 \pm 0.4 \mathrm{~cm}^{2}$. Out of 53 patients with available data, 52 had none or mild aortic regurgitation.

\section{CLINICAL OUTCOMES}

A trend towards better clinical outcomes was observed in the SAPIEN 3 group. All-cause mortality at thirty days was $0.6 \%$ and $3.5 \%$ in SAPIEN 3 and SAPIEN XT patients, respectively $(\mathrm{p}=0.077)$ (Table 2). Acute kidney injury stages 2-3 became
Table 2. Periprocedural parameters and outcomes.

\begin{tabular}{|c|c|c|c|c|}
\hline \multicolumn{2}{|c|}{ Variable } & SAPIEN XT & SAPIEN 3 & $p$-value \\
\hline \multicolumn{2}{|c|}{ Transfemoral access } & $\begin{array}{c}58.5 \% \\
(53.3-63.6)\end{array}$ & $\begin{array}{c}88.2 \% \\
(82.8-93.6)\end{array}$ & $<0.001$ \\
\hline \multicolumn{2}{|c|}{ General anaesthesia } & $\begin{array}{c}75.0 \% \\
(70.5-79.5)\end{array}$ & $\begin{array}{c}52.5 \% \\
(43.3-61.6)\end{array}$ & $<0.001$ \\
\hline \multicolumn{2}{|l|}{ TEE guidance } & $\begin{array}{c}74.7 \% \\
(70.2-79.2)\end{array}$ & $\begin{array}{c}53.5 \% \\
(44.4-62.7)\end{array}$ & $<0.001$ \\
\hline \multicolumn{2}{|l|}{ Predilation } & $\begin{array}{c}29.3 \% \\
(24.5-34.1)\end{array}$ & $\begin{array}{c}27.0 \% \\
(19.2-34.7)\end{array}$ & 0.618 \\
\hline \multirow{4}{*}{$\begin{array}{l}\text { THV } \\
\text { external } \\
\text { diameter }^{\mathrm{a}}\end{array}$} & $20 \mathrm{~mm}$ & $3.0 \%(1.2-4.7)$ & $1.3 \%(0.0-3.0)$ & \multirow{4}{*}{0.395} \\
\hline & $23 \mathrm{~mm}$ & $\begin{array}{c}60.2 \% \\
(55.0-65.4)\end{array}$ & $\begin{array}{c}67.8 \% \\
(59.5-76.1)\end{array}$ & \\
\hline & $26 \mathrm{~mm}$ & $\begin{array}{c}31.1 \% \\
(26.1-36.1)\end{array}$ & $\begin{array}{c}25.4 \% \\
(17.5-33.2)\end{array}$ & \\
\hline & $29 \mathrm{~mm}$ & $5.7 \%(3.2-8.2)$ & $5.6 \%(2.0-9.1)$ & \\
\hline \multicolumn{2}{|l|}{ Post-dilation } & $4.7 \%(1.7-7.7)$ & $1.2 \%(0.0-2.5)$ & 0.033 \\
\hline \multicolumn{2}{|c|}{ Second valve required } & $3.2 \%(1.3-5.2)$ & $0.4 \%(0.0-1.3)$ & 0.052 \\
\hline \multicolumn{2}{|l|}{ Malposition } & $2.5 \%(0.8-4.3)$ & $1.5 \%(0.0-3.3)$ & 0.446 \\
\hline \multirow[t]{3}{*}{ Residual AR } & $\begin{array}{l}\text { None/ } \\
\text { trace }\end{array}$ & $\begin{array}{c}69.6 \% \\
(64.7-74.5)\end{array}$ & $\begin{array}{c}85.4 \% \\
(79.3-91.5)\end{array}$ & \multirow{3}{*}{$<0.001$} \\
\hline & Mild & $\begin{array}{c}25.2 \% \\
(20.3-30.1)\end{array}$ & $\begin{array}{c}12.5 \% \\
(7.4-17.6) \\
\end{array}$ & \\
\hline & $>$ Mild & $5.2 \%(2.3-8.1)$ & $2.1 \%(0.5-3.8)$ & \\
\hline \multicolumn{2}{|c|}{ Indexed EOA $\left(\mathrm{cm}^{2} / \mathrm{m}^{2}\right)^{\mathrm{c}}$} & $\begin{array}{c}0.745 \\
(0.713-0.777)\end{array}$ & $\begin{array}{c}0.816 \\
(0.766-0.866)\end{array}$ & 0.018 \\
\hline \multicolumn{2}{|c|}{$\begin{array}{l}\text { AV gradient mean } \\
(\mathrm{mmHg})^{d}\end{array}$} & $\begin{array}{c}17.4 \\
(16.5-18.3) \\
\end{array}$ & $\begin{array}{c}16.9 \\
(15.4-18.3) \\
\end{array}$ & 0.536 \\
\hline \multicolumn{2}{|c|}{ Device success } & $\begin{array}{c}95.1 \% \\
(92.8-97.4) \\
\end{array}$ & $\begin{array}{c}99.3 \% \\
(97.8-100.0) \\
\end{array}$ & 0.062 \\
\hline \multicolumn{2}{|l|}{ Major stroke } & $2.0 \%(0.5-3.4)$ & $0.5 \%(0.0-1.4)$ & 0.184 \\
\hline \multicolumn{2}{|c|}{$\begin{array}{l}\text { Major/life-threatening } \\
\text { bleeding }\end{array}$} & $6.0 \%(3.5-8.4)$ & $1.9 \%(0.0-4.1)$ & 0.065 \\
\hline \multicolumn{2}{|c|}{$\begin{array}{l}\text { Major vascular } \\
\text { complication }\end{array}$} & $\begin{array}{c}7.5 \% \\
(4.8-10.2)\end{array}$ & $\begin{array}{c}6.9 \% \\
(2.9-10.8)\end{array}$ & 0.805 \\
\hline \multicolumn{2}{|c|}{$\begin{array}{l}\text { Acute kidney injury } \\
\text { (stages } 2+\text { ) }\end{array}$} & $\begin{array}{c}7.9 \% \\
(5.1-10.6)\end{array}$ & $3.5 \%(0.4-6.6)$ & 0.093 \\
\hline \multicolumn{2}{|c|}{$\begin{array}{l}\text { Permanent pacemaker } \\
\text { implantation }\end{array}$} & $2.5 \%(0.9-4.1)$ & $\begin{array}{c}6.0 \% \\
(1.8-10.2)\end{array}$ & 0.071 \\
\hline \multicolumn{2}{|c|}{ NYHA I-II (at 30 days) } & $\begin{array}{c}92.2 \% \\
(88.9-95.4)\end{array}$ & $\begin{array}{c}96.1 \% \\
(92.4-99.7)\end{array}$ & 0.180 \\
\hline \multicolumn{2}{|c|}{$\begin{array}{l}\text { All-cause mortality } \\
\text { (at } 30 \text { days) }\end{array}$} & $3.5 \%(1.6-5.4)$ & $0.6 \%(0.0-1.7)$ & 0.077 \\
\hline
\end{tabular}

Values for binary parameters estimated using logistic regression. Values are presented as marginal predictions or marginal means with $95 \%$ confidence intervals in parentheses. ${ }^{a}$ Values for THV external diameter estimated by multinomial logit. ' $V a l u e s$ for residual AR estimated by ordinal logit. 'Values for indexed EOA estimated by identity Poisson GLM. ${ }^{d}$ Values for AV gradient mean estimated by identity-inverse Gaussian GLM. AV: aortic valve; AR: aortic regurgitation; EOA: effective orifice area; GLM: generalised linear model; NYHA: New York Heart Association (functional class); TEE: transoesophageal echocardiography; THV: transcatheter heart valve

prevalent in $3.5 \%$ vs. $7.9 \%(\mathrm{p}=0.093)$, while major/life-threatening bleeding occurred in $1.9 \%$ of SAPIEN 3 vs. $6.0 \%$ of SAPIEN XT cases $(\mathrm{p}=0.065)$. Outcomes were similar regarding rates of major stroke $(0.5 \%$ vs. $2.0 \%, \mathrm{p}=0.184)$ or major vascular/ access-site complications $(6.9 \%$ vs. $7.5 \%, \mathrm{p}=0.805)$. The rate of 

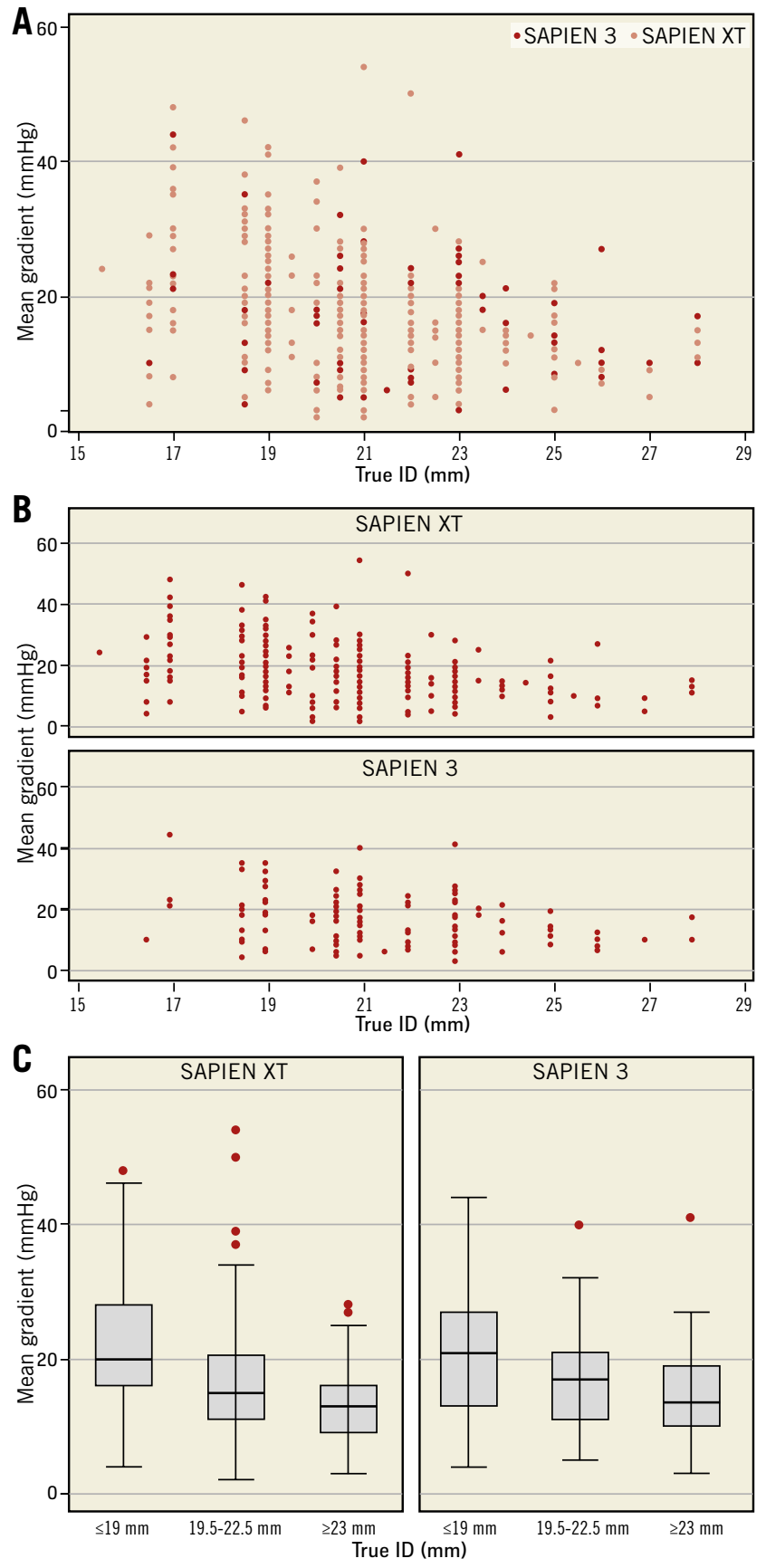

Figure 1. Post valve-in-valve mean gradient according to surgical valve internal diameter. A) \& B) Post-procedural gradients according to the true inner diameter (ID) of degenerated surgical bioprostheses for the SAPIEN 3 and the SAPIEN XT transcatheter heart valves. Higher rates of elevated gradients were observed with both devices after implantation in small bioprostheses with $\leq 21 \mathrm{~mm}$ inner diameter (SAPIEN 3: $p=0.02$, SAPIEN XT: $p=0.01$ ).

$C)$ Subgroup analysis showing the significant association of mean gradients and true ID ( $p<0.01$ in SAPIEN XT and SAPIEN 3).

permanent pacemaker implantations was higher in SAPIEN 3 than in SAPIEN XT patients $(6.0 \%$ vs. $2.5 \%$ in patients without a permanent pacemaker prior to $\mathrm{VinV}, \mathrm{p}=0.071$ ). Indications for pacemaker implantation in SAPIEN 3 patients were an intermittent or



Figure 2. SAPIEN 3 valve-in-valve implantation depth. VinV implantation of a $23 \mathrm{~mm}$ SAPIEN 3 THV into a $21 \mathrm{~mm}$ PERIMOUNT bioprosthesis at $36 \%$ and $15.5 \%$ depth, yielding a 35 and $18 \mathrm{mmHg}$ mean transvalvular gradient, respectively.

persistent complete heart block in seven cases and a combined left bundle branch block and prolonged first-degree atrioventricular block in one patient. Of note, three of these patients displayed a pre-existing right bundle branch block at baseline. Six out of eight pacemaker implantations were performed in patients with a low implanted SAPIEN 3, and a cut-off of deeper implantation than $5 \mathrm{~mm}$ was identified as associated with increased risk (depth $\leq 5 \mathrm{~mm} \mathrm{4 \%}$ vs. depth $>5 \mathrm{~mm} \mathrm{22.2 \% ;}=0.01$ ) (Figure 3B). Out of 90 SAPIEN 3 patients with available one-year information, 16 had died $(17.8 \%)$.

\section{Discussion}

The data represent the first large analysis of aortic VinV implantations with the latest-generation SAPIEN 3, comparing it to a similar cohort of SAPIEN XT VinV procedures. Baseline parameters and the IPT propensity score weighting suggest that the two cohorts are generally similar. Three major findings can be drawn from this analysis: (i) VinV implantation using the SAPIEN 3 was safe, (ii) elevated residual gradients remain a concern with both balloon-expandable THV (particularly in small surgical prostheses), and (iii) higher SAPIEN 3 implantation within degenerated bioprostheses may be beneficial.

Compared to the SAPIEN XT, VinV procedures using the SAPIEN 3 THV were both equally safe and effective for the treatment of degenerated aortic bioprostheses. With smaller delivery sheaths, procedures in the SAPIEN 3 group were more often performed via transfemoral access under local anaesthesia and without transoesophageal echocardiographic guidance.

Short-term clinical follow-up demonstrated low early mortality and low periprocedural complication rates in both groups, underlining the high safety profile of the procedure. A trend towards fewer events of bleeding, acute kidney injury and 30-day mortality in the SAPIEN 3 group may reflect the learning curve and substantial procedural and device-based refinements that have 
A

SAPIEN 3 - Mean gradient and depth of implantation

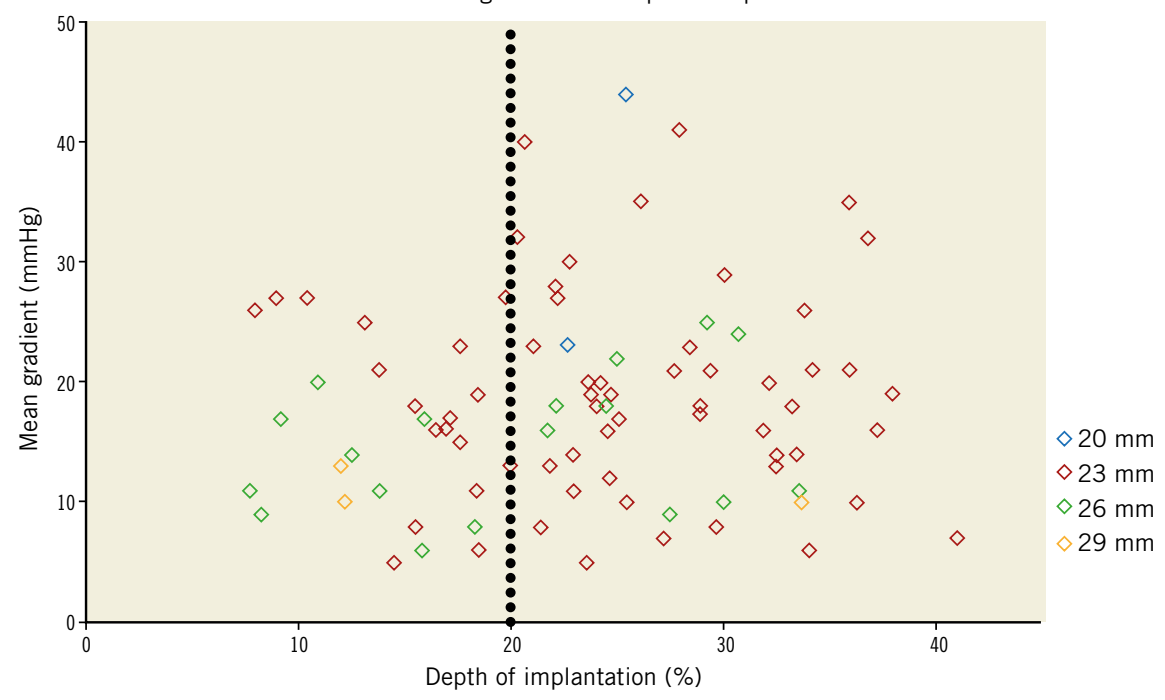

B

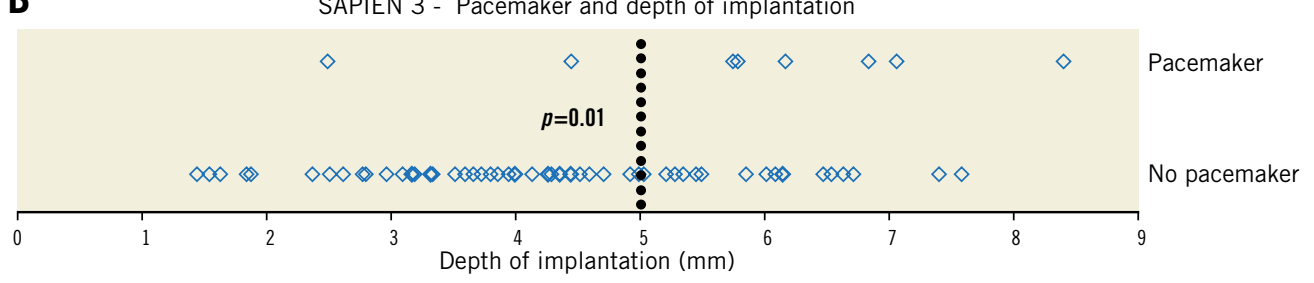

Figure 3. SAPIEN 3 valve-in-valve implantation depth and clinical outcomes. A) Post-procedural gradients after VinV with the SAPIEN 3 according to implantation depth as a function of \% total SAPIEN 3 frame length. Implantation depth $>20 \%$ was associated with a mean gradient $\geq 30 \mathrm{mmHg}$ in $13.8 \%$ of patients compared to none after implantation depth $\leq 20 \%(p=0.049)$. B) Six out of eight pacemaker implantations were performed after low SAPIEN 3 implantation ( $>5 \mathrm{~mm}, \mathrm{p}=0.01$ ).

been achieved in the meantime. In addition, rates of post-dilation or the need for a second THV were low with both platforms and in favour of the SAPIEN 3. Predilation of the degenerated bioprostheses was reported in $29.3 \%$ of procedures. Due to the inherent risk of predilation-associated embolisation and the negligible number of cases with difficulties in crossing the prosthesis, this number appears unreasonably high. The detrimental effect of paravalvular regurgitation on long-term outcome has been investigated $^{9}$. Rates of residual regurgitation were low with both devices; the additional sealing cuff of the SAPIEN 3 may have facilitated even lower rates in this group compared to the SAPIEN XT. In two cases, the SAPIEN 3 facilitated the treatment of paraprosthetic regurgitation in degenerated bioprostheses. Its design featuring an additional cuff at the inflow portion may allow sufficient sealing of paravalvular leaks if implanted low enough. The rate of pacemaker implantations after VinV was higher in the SAPIEN 3 group compared to SAPIEN XT patients. The longer device frame of the next-generation SAPIEN 3 THV may have contributed to this result as an association of implantation depth and pacemaker implantations was demonstrated. It should be noted that early SAPIEN 3 cases were included in this analysis. As such, results may also have been influenced by a learning curve regarding implantation depth and foreshortening of the SAPIEN 3 THV frame. In addition, a pre-existent right bundle branch block was evident in a relevant number of these patients, increasing the risk for conduction disturbances yielding permanent pacemaker implantations.

Residual aortic valve stenosis remains the Achilles' heel of VinV implantation. Elevated gradients after VinV procedures were reported before and were inversely related to the internal diameter of the surgical bioprostheses ${ }^{2,3}$. This observation was substantiated by our analysis. The non-distensible valve prosthesis stents limit the THV expansion with residual higher gradients than after implantation in native aortic valves. We noted elevated gradients in approximately one third of patients after VinV with the SAPIEN 3, similar to the SAPIEN XT in this analysis. Prosthesispatient mismatch and low rates of device success (VARC-defined) remain an issue in a significant number of patients, particularly in smaller bioprostheses with internal diameters of $21 \mathrm{~mm}$ or less. Previous analyses from the VIVID registry ${ }^{10}$ and in vitro experiments ${ }^{11}$ noted lower residual gradients for THV featuring a supraannular design, particularly in small bioprostheses. In vitro studies demonstrated that high deployment of intra-annular THV may also reduce transvalvular gradients, at the risk, however, of valve embolisation $^{12}$. Our data suggest that low implantation of the nextgeneration SAPIEN 3 ( $>20 \%$ THV stent frame length) may yield 
higher residual gradients, particularly in small prostheses. Hence, care should be taken to position the SAPIEN 3 precisely within the bioprosthesis' ring. Similar observations were reported for the SAPIEN XT and Medtronic CoreValve ${ }^{8}$. Comprehensive knowledge of valve design and dimensions to achieve precise implantation of the THV into the surgical bioprostheses at the desired height remains essential to achieve favourable haemodynamic outcomes. Although the influence of elevated gradients on longterm clinical outcome and durability of the THV remains to be determined, data from surgical aortic valve replacement strongly suggest an adverse impact of prosthesis-patient mismatch on longterm survival ${ }^{13}$. As we are already observing an expansion of VinV treatment to intermediate-risk and younger patients, favourable haemodynamic results without any residual stenosis after VinV implantation are essential to achieve good long-term outcomes. Of note, prosthesis-patient mismatch due to surgical aortic valve replacement with undersized bioprostheses (in relation to the body surface area) should probably be treated rarely using VinV therapy, particularly with intra-annular THV.

\section{Limitations}

The current analysis provides the most comprehensive analysis of SAPIEN 3 THV for VinV treatment to date. Nevertheless, important limitations should be noted. This is a retrospective and observational analysis, including the early experience with the SAPIEN 3 for VinV treatment, and limited to acute data. Although the cohorts appeared similar before and after IPT weighting, small baseline covariate imbalances remained. In addition, propensity score weighting and matching procedures are unable to address unobserved confounding. A broad range of degenerated prostheses treated by VinV therapy impeded an exact match according to specific surgical prostheses. Clinical outcomes and echocardiographic measurements were site-reported. No information was available on whether balloon underfilling was performed on the cases included. Due to insufficient resolution, perpendicularity or the lack of radiopaque markers, depth analysis was not performed in all SAPIEN 3 cases. Subsequently, the ROC analysis of optimal implantation depth resulted in modest AUC values. Comparison of SAPIEN 3 with other THV devices was beyond the scope of the current analysis, and haemodynamic benefits of supra-annular over intra-annular THV devices have already been extensively described by other studies ${ }^{8,10}$.

\section{Conclusions}

In conclusion, transcatheter aortic VinV implantation was similarly safe and effective using the next-generation SAPIEN 3 and the predecessor SAPIEN XT. However, residual stenosis remains a concern with balloon-expandable VinV procedures, particularly when performed in smaller bioprostheses. Low implantation of the SAPIEN 3 was associated with elevated gradients and pacemaker implantations. Hence, careful patient selection and device positioning are crucial to achieve favourable results with these devices.

\section{Impact on daily practice}

Balloon-expandable VinV with both previous-generation and current-generation devices is safe, but still gives rise to considerable issues, such as residual stenosis and need for pacemaker implantation. The development of future-generation balloon-expandable devices should take into consideration the long-standing issues that have not been solved by current-generation devices, especially in the context of VinV.

\section{Acknowledgements}

We would like to thank Alex Woersching, $\mathrm{PhD}$ candidate at the University of Washington, for his assistance in revising the statistical methods of this paper.

\section{Conflict of interest statement}

S. Ensminger is a consultant for Edwards Lifesciences. V. Bapat is a consultant for Edwards Lifesciences, Boston Scientific, Medtronic and Sorin, and has received research grants from Boston Scientific. D. Dvir is a consultant to Edwards Lifesciences, Medtronic and St. Jude Medical. The other authors have no conflicts of interest to declare.

\section{References}

1. Hickey GL, Bridgewater B, Grant SW, Deanfield J, Parkinson J, Bryan AJ, Dalrymple-Hay M, Moat N, Buchan I, Dunning J. National Registry Data and Record Linkage to Inform Postmarket Surveillance of Prosthetic Aortic Valve Models Over 15 Years. JAMA Intern Med. 2017;177:79-86.

2. Dvir D, Webb JG, Bleiziffer S, Pasic M, Waksman R, Kodali S, Barbanti M, Latib A, Schaefer U, Rodés-Cabau J, Treede H, Piazza N, Hildick-Smith D, Himbert D, Walther T, Hengstenberg C, Nissen H, Bekeredjian R, Presbitero P, Ferrari E, Segev A, de Weger A, Windecker S, Moat NE, Napodano M, Wilbring M, Cerillo AG, Brecker S, Tchetche D, Lefèvre T, De Marco F, Fiorina C, Petronio AS, Teles RC, Testa L, Laborde JC, Leon MB, Kornowski R; Valve-inValve International Data Registry Investigators. Transcatheter aortic valve implantation in failed bioprosthetic surgical valves. JAMA. 2014;312:162-70.

3. Seiffert M, Conradi L, Baldus S, Knap M, Schirmer J, Franzen O, Koschyk D, Meinertz T, Reichenspurner H, Treede H. Impact of patient-prosthesis mismatch after transcatheter aortic valve-in-valve implantation in degenerated bioprostheses. J Thorac Cardiovasc Surg. 2012;143:617-24.

4. De Torres-Alba F, Kaleschke G, Diller GP, Vormbrock J, Orwat S, Radke R, Reinke F, Fischer D, Reinecke H, Baumgartner H. Changes in the Pacemaker Rate After Transition From Edwards SAPIEN-XT to SAPIEN-3 Transcatheter Aortic Valve Implantation. JACC Cardiovasc Interv. 2016;9:805-13.

5. Zoghbi WA, Chambers JB, Dumesnil JG, Foster E, Gottdiener JS, Grayburn PA, Khandheria BK, Levine RA, Marx GR, Miller FAJr, Nakatani S, Quiñones MA, Rakowski H, Rodriguez LL, Swaminathan M, Waggoner AD, Weissman NJ, Zabalgoitia M; 
American Society of Echocardiography's Guidelines and Standards Committee; Task Force on Prosthetic Valves; American College of Cardiology Cardiovascular Imaging Committee; Cardiac Imaging Committee of the American Heart Association; European Association of Echocardiography; European Society of Cardiology; Japanese Society of Echocardiography; Canadian Society of Echocardiography; American College of Cardiology Foundation; American Heart Association; European Association of Echocardiography; European Society of Cardiology; Japanese Society of Echocardiography; Canadian Society of Echocardiography. Recommendations for evaluation of prosthetic valves with echocardiography and doppler ultrasound: a report From the American Society of Echocardiography's Guidelines and Standards Committee and the Task Force on Prosthetic Valves, developed in conjunction with the American College of Cardiology Cardiovascular Imaging Committee, Cardiac Imaging Committee of the American Heart Association, the European Association of Echocardiography, a registered branch of the European Society of Cardiology, the Japanese Society of Echocardiography and the Canadian Society of Echocardiography, endorsed by the American College of Cardiology Foundation, American Heart Association, European Association of Echocardiography, a registered branch of the European Society of Cardiology, the Japanese Society of Echocardiography, and Canadian Society of Echocardiography. J Am Soc Echocardiogr. 2009;22:975-1014.

6. Bapat V. Valve-in-valve apps: why and how they were developed and how to use them. EuroIntervention. 2014;10:U44-51.

7. Kappetein AP, Head SJ, Généreux P, Piazza N, van Mieghem NM, Blackstone EH, Brott TG, Cohen DJ, Cutlip DE, van Es G, Hahn RT, Kirtane AJ, Krucoff MW, Kodali S, Mack MJ, Mehran R, Rodés-Cabau J, Vranckx P, Webb JG, Windecker S, Serruys PW, Leon MB. Updated standardized endpoint definitions for transcatheter aortic valve implantation: the Valve Academic Research Consortium-2 consensus document. Eur Heart J. 2012;33: 2403-18.

8. Simonato M, Webb J, Kornowski R, Vahanian A, Frerker C, Nissen H, Bleiziffer S, Duncan A, Rodés-Cabau J, Attizzani GF, Horlick E, Latib A, Bekeredjian R, Barbanti M, Lefevre T, Cerillo A, Hernández JM, Bruschi G, Spargias K, Iadanza A, Brecker S, Palma JH, Finkelstein A, Abdel-Wahab M, Lemos P, Petronio AS, Champagnac D, Sinning JM, Salizzoni S, Napodano M, Fiorina C, Marzocchi A, Leon MB, Dvir D. Transcatheter Replacement of Failed Bioprosthetic Valves: Large Multicenter Assessment of the Effect of Implantation Depth on
Hemodynamics After Aortic Valve-in-Valve. Circ Cardiovasc Interv. 2016 Jun;9(6).

9. Kodali S, Pibarot P, Douglas PS, Williams $\mathrm{M}, \mathrm{Xu} \mathrm{K}$, Thourani V, Rihal CS, Zajarias A, Doshi D, Davidson M, Tuzcu EM, Stewart W, Weissman NJ, Svensson L, Greason K, Maniar H, Mack M, Anwaruddin S, Leon MB, Hahn RT. Paravalvular regurgitation after transcatheter aortic valve replacement with the Edwards sapien valve in the PARTNER trial: characterizing patients and impact on outcomes. Eur Heart J. 2015;36:449-56.

10. Dvir D, Webb J, Brecker S, Bleiziffer S, Hildick-Smith D, Colombo A, Descoutures F, Hengstenberg C, Moat NE, Bekeredjian R, Napodano M, Testa L, Lefevre T, Guetta V, Nissen H, Hernández JM, Roy D, Teles RC, Segev A, Dumonteil N, Fiorina C, Gotzmann M, Tchetche D, Abdel-Wahab M, De Marco F, Baumbach A, Laborde JC, Kornowski R. Transcatheter aortic valve replacement for degenerative bioprosthetic surgical valves: results from the global valve-invalve registry. Circulation. 2012;126:2335-44.

11. Sedaghat A, Sinning JM, Utzenrath M, Ghalati PF, Schmitz C, Werner N, Nickenig G, Grube E, Ensminger S, Steinseifer U, Kuetting M. Hydrodynamic Performance of the Medtronic CoreValve and the Edwards SAPIEN-XT Transcatheter Heart Valve in Surgical Bioprostheses: An In Vitro Valve-in-Valve Model. Ann Thorac Surg. 2016;101:118-24.

12. Midha PA, Raghav V, Condado JF, Arjunon S, Uceda DE, Lerakis S, Thourani VH, Babaliaros V, Yoganathan AP. How Can We Help a Patient With a Small Failing Bioprosthesis?: An In Vitro Case Study. JACC Cardiovasc Interv. 2015;8:2026-33.

13. Head SJ, Mokhles MM, Osnabrugge RL, Pibarot P, Mack MJ, Takkenberg JJ, Bogers AJ, Kappetein AP. The impact of prosthesispatient mismatch on long-term survival after aortic valve replacement: a systematic review and meta-analysis of 34 observational studies comprising 27186 patients with 133141 patient-years. Eur Heart J. 2012;33:1518-29.

\section{Supplementary data}

Supplementary Appendix. Methods.

Supplementary Table 1 . Type of degenerated bioprostheses treated by VinV procedures.

Supplementary Figure 1. Kernel density plot of propensity scores for SAPIEN 3 and SAPIEN XT patients.

\section{The supplementary data are published online at: http://www.pcronline.com/ eurointervention/137th_issue/71}




\section{Supplementary data}

\section{Supplementary Appendix. Methods.}

Statistical analysis and inverse probability of treatment weighting process

Baseline characteristics are summarised for SAPIEN 3 and SAPIEN XT patients by means and standard deviations for continuous variables and counts and percentages for binary and categorical variables (Table 1). Differences are reported as effect sizes or standardised differences computed as the difference between means divided by the full sample standard deviation for continuous variables and the corresponding formula for binary variables and levels of categorical variables. Effect sizes of $0.2,0.5$, and 0.8 are generally considered small, medium, and large, respectively. Guidelines for propensity score analyses including IPT weights recommend using effect sizes to assess balance of covariates between treatment and control groups rather than conducting significance testing. Authors have suggested that effect sizes with an absolute value $<0.1$ indicate negligible imbalance of covariates between treatment groups.

Since VIVID includes patients nested within centres within countries, the propensity score of being a SAPIEN 3 patient was estimated by a saturated logistic regression generalised estimating equation model clustered on country of surgery, which accounts for correlation of prosthesis received within centre and country. The saturated model adjusts for main effects parameters: patient age, gender, renal insufficiency diagnosis (glomerular filtration rate $<60$ $\mathrm{mL} / \mathrm{min}$ ), diabetes mellitus, prior cerebrovascular event, peripheral vascular disease, left ventricular ejection fraction, and STS-PROM score. In addition to main effects, the model also included squared terms for continuous main effects parameters and one-way interactions between all pairs of main effects parameters. We a priori decided to exclude observations from outcomes models that fell out of the region of propensity score common support defined 
as SAPIEN XT patients with propensity scores more than 0.1 less than the smallest SAPIEN 3 propensity score and SAPIEN 3 patients with propensity score more than 0.1 larger than the largest SAPIEN XT propensity score. We computed the IPT weights as the reciprocal of the probability of receiving the prosthesis (SAPIEN 3 or XT) that was actually received. Table 1 reports the differences in baseline characteristics accounting for the IPT weights.

To estimate the effects of SAPIEN 3 use on periprocedural parameters and clinical outcomes, we used appropriate weighted regression models for the different outcome types. Binary outcomes were modelled by logistic regressions. THV external diameter (20, 23, 26, or 29 mm) was modelled by multinomial logit. Modified Park tests (MPT) were conducted to determine the appropriate generalised linear model for the two continuous outcomes - iEOA (MPT coefficient of the log of the raw-scale prediction=1.18) and aortic mean gradient (MPT coefficient=3.88). Accordingly, a linear Poisson model and linear-inverse Gaussian model were used for iEOA and aortic mean gradient, respectively. For the ordinal outcome residual aortic regurgitation (none/trace, mild, or greater than mild), ordinal logit was used. Effects are reported as predicted likelihoods for binary and categorical variables and predicted means for continuous outcomes for each SAPIEN 3 and SAPIEN XT (also known as predictive margins or recycled predictions), which are population-averaged marginal predictions of the outcomes. All outcomes models were estimated with robust standard errors. Statistical analyses were performed using Stata version 14.2. 
Supplementary Figure 1. Kernel density plot of propensity scores for SAPIEN 3 and SAPIEN XT patients.

Kernel densities of propensity scores for SAPIEN 3 and SAPIEN XT patients showing propensity scores from 0.18 to 0.81 for SAPIEN XT with median 0.23 and from 0.058 to 0.52 for SAPIEN 3 with median 0.26 .

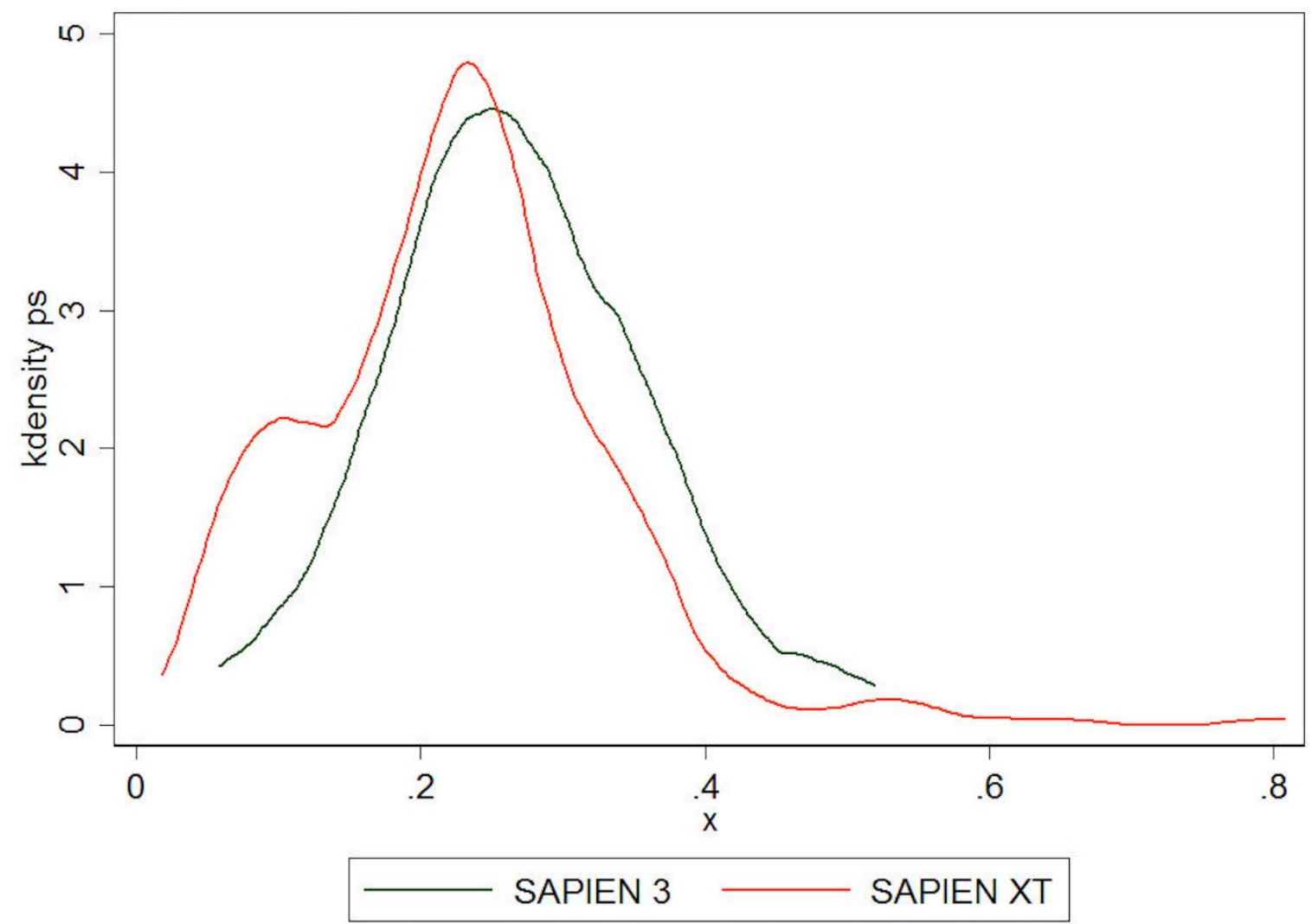


Supplementary Table 1. Types of degenerated bioprosthesis treated by VinV procedures.

\begin{tabular}{|c|c|c|c|}
\hline & SAPIEN XT & SAPIEN 3 & Total \\
\hline CE PERIMOUNT & $82(22.2 \%)$ & $44(30.6 \%)$ & $126(24.5 \%)$ \\
\hline Sorin Mitroflow & $60(16.2 \%)$ & $9(6.3 \%)$ & $69(13.4 \%)$ \\
\hline Medtronic Mosaic & $39(10.5 \%)$ & $17(11.8 \%)$ & $56(10.9 \%)$ \\
\hline Carpentier-Edwards Classic & $42(11.4 \%)$ & $11(7.6 \%)$ & $53(10.3 \%)$ \\
\hline Medtronic Hancock & $21(5.7 \%)$ & $21(14.6 \%)$ & $42(8.2 \%)$ \\
\hline Medtronic Freestyle & $21(5.7 \%)$ & $14(9.7 \%)$ & $35(6.8 \%)$ \\
\hline St. Jude Epic & $22(5.9 \%)$ & $5(3.5 \%)$ & $27(5.3 \%)$ \\
\hline Homograft & $17(4.6 \%)$ & $3(2.1 \%)$ & $20(3.9 \%)$ \\
\hline CE PERIMOUNT Magna & $11(3 \%)$ & $1(0.7 \%)$ & $12(2.3 \%)$ \\
\hline Baxter-Edwards & $6(1.6 \%)$ & $2(1.4 \%)$ & $8(1.6 \%)$ \\
\hline Sorin Freedom & $3(0.8 \%)$ & $5(3.5 \%)$ & $8(1.6 \%)$ \\
\hline St. Jude SPV Toronto & $7(1.9 \%)$ & $0(0 \%)$ & $7(1.4 \%)$ \\
\hline Sorin Perceval & $6(1.6 \%)$ & $1(0.7 \%)$ & $7(1.4 \%)$ \\
\hline St. Jude Trifecta & $4(1.1 \%)$ & $3(2.1 \%)$ & $7(1.4 \%)$ \\
\hline Labcor & $5(1.4 \%)$ & $0(0 \%)$ & $5(1 \%)$ \\
\hline Sorin Pericarbon & $5(1.4 \%)$ & $0(0 \%)$ & $5(1 \%)$ \\
\hline Sorin Soprano & $3(0.8 \%)$ & $2(1.4 \%)$ & $5(1 \%)$ \\
\hline BioValsalva & $1(0.3 \%)$ & $2(1.4 \%)$ & $3(0.6 \%)$ \\
\hline ATS 3F & $0(0 \%)$ & $2(1.4 \%)$ & $2(0.4 \%)$ \\
\hline Bravo Cardiovascular & $2(0.5 \%)$ & $0(0 \%)$ & $2(0.4 \%)$ \\
\hline Medtronic Intact & $2(0.5 \%)$ & $0(0 \%)$ & $2(0.4 \%)$ \\
\hline Unknown & $3(0.8 \%)$ & $0(0 \%)$ & $3(0.6 \%)$ \\
\hline Others & $8(2.2 \%)$ & $2(1.4 \%)$ & $10(1.9 \%)$ \\
\hline TOTAL & $370(100 \%)$ & $144(100 \%)$ & $514(100 \%)$ \\
\hline
\end{tabular}

